\title{
Demand-Side Management of Solar Microgrid Operation: Effect of Time-of-Use Pricing and Incentives
}

\author{
Godiana Hagile Philipo $\mathbb{D}^{1,2,3}$ Yusufu Abeid Chande Jande $\mathbb{D}^{1,2}$ and Thomas Kivevele $\mathbb{C}^{1,2}$ \\ ${ }^{1}$ Department of Materials and Energy Science and Engineering, Nelson Mandela African Institution of Science and Technology, \\ P.O. Box 447, Arusha, Tanzania \\ ${ }^{2}$ Water Infrastructure and Sustainable Energy Futures, Nelson Mandela African Institution of Science and Technology, \\ Nelson Mandela Rd, P.O. Box 9124, Arusha, Tanzania \\ ${ }^{3}$ Electrical Engineering Department, Saint Augustine University of Tanzania, P.O. Box 307, Mwanza, Tanzania
}

Correspondence should be addressed to Thomas Kivevele; thomas.kivevele@nm-aist.ac.tz

Received 14 November 2019; Revised 4 February 2020; Accepted 25 February 2020; Published 5 June 2020

Academic Editor: Abhijeet. P. Borole

Copyright ( 2020 Godiana Hagile Philipo et al. This is an open access article distributed under the Creative Commons Attribution License, which permits unrestricted use, distribution, and reproduction in any medium, provided the original work is properly cited.

\begin{abstract}
Over $17 \%$ of the world's population lack access to electricity, the majority being in rural areas of sub-Saharan Africa and South Asia. Microgrid technologies are a promising solution towards rural and remote area electrification; however, ever-increasing electricity demand remains a big challenge leading to pronounced power outages. Demand-side management is an indispensable tool towards addressing the challenges. This paper employs a mathematical model based on incentives and time-of-use rates to simulate daily power usage pattern of residential customers using data collected from an isolated village Ngurdoto solar microgrid, Arusha, Tanzania. Customer responsiveness on the increase in price was evaluated based on the concept of price elasticity of demand. Using two demand response strategies, namely, load shifting (LS) and scheduled load reduction (SLR), the results reveal that LS can achieve up to $4.87 \%$ energy-saving, $19.23 \%$ cost-saving, and about $31 \%$ and $19 \%$ peak reduction and power factor improvement, respectively. SLR method resulted in about $19 \%$ energy-saving, $49 \%$ cost-saving, and $24 \%$ power factor improvement. Thus, the results presented in this study may lead to a more efficient and stable system than the current state in developing countries' utility.
\end{abstract}

\section{Introduction}

Electrical energy is the backbone for development worldwide, and for many decades, it has been used to power industries and homes [1]. Developing countries, particularly sub-Saharan Africa, face severe lack of access to reliable electricity supply when compared with other parts of the world [2]. In particular, remote areas are likely to suffer from unreliable and insufficient power supply. The situation is most critical for the people living in rural areas where the national grid is not accessible. It is estimated that $87 \%$ of the rural population in developing countries may not have access to electricity by 2030, while developed countries contribute only $13 \%$ [3]. Despite the fact that more than $70 \%$ of the population in Tanzania live in rural areas per 2012 census, only $5.3 \%$ of households have access to electricity through the national grid [4]. The statistics of the year 2016 show that Tanzania made some progress; nearly $33 \%$ of the population had access to electricity in comparison with $20 \%$ of 2014 [5]. However, the registered increase in electrification is growing at low rates, which is attributed to long physical distance from the main grid to the consumption site [6], isolated or scattered villages $[3,7]$. The deployment of microgrids may improve local reliability and high levels of quality supply, eventually resulting in reduced power losses over the distribution network [8], thus improving electrification for remote areas, for example, a $90 \mathrm{~kW}$ solar hybrid minigrid located in the isolated island of Ukerewe in Mwanza, Tanzania, covers about $80 \%$ of the island's electricity demand [9]. Thus, microgrids can be regarded as a 
viable alternative in promoting rural and scattered settlement electrification [10].

Furthermore, the paradigm shift allows some flexibility towards electricity supply and demand in both rural and urban areas $[11,12]$. However, deployment of microgrids raises challenges regarding stability and reliability as a result of their intermittent nature and the stochastic behaviour of energy needed to power loads $[13,14]$. It has been reported that, when supply cannot cater for the massive increase in demand, utilities interrupt energy supply through load shedding [15]. The traditional load shedding has been a terrifying experience to customers and loss to utility and may not work efficiently in a contingency [16]. The most popular alternatives to resolve the challenges are through the use of storage systems, load curtailment, and demand-side management (DSM) [17, 18]. Storage systems have been proven to be the most expensive technology worldwide, while load curtailment reduces system utilisation factor, making the system unable to attain cost recovery [2]. Through DSM, loads can be fully controllable; the utilisation factor can increase with a reduction in cost. During critical hours, DSM can be implemented for optimal microgrid operation and also utilities can significantly reduce vast amounts of value of lost load [19]. Thus, DSM is an indispensable tool that can guarantee the feasible and economic operation of any microgrid [19].

DSM, being categorised as energy management and demand management (Figure 1), has become an essential tool for controlling demand at user end [20]. If different strategies can be implemented through DSM such as the inclusion of electricity tariffs [21], incentives [22], and penalties [23], power-saving technologies and government policies $[24,25]$ can significantly improve electricity consumption status in developing countries.

Demand management targets the demand profile; it can be grouped into three, as can be seen from Figure 1 [26]. In direct load control (DLC), utilities can remotely shut down some of the loads during high consumption to avoid system collapse while load shifting (LS) makes use of the time dependence of loads and eventually shifts loads from peak to off-peak times [27]. Peak clipping and valley filling are used to reduce peak and fill the off-peak demands, respectively.

In the incentive-based strategy, tariff and penalty mechanisms are implemented whereby a customer is incentivised for reducing loads and penalised for using excess loads during peak periods. The common pricing mechanism which can be used to achieve several demand response programs (DRPs) such as LS and DLC is the time of use (TOU). TOU tariffs are used to encourage customers to regulate their electricity usage in order to benefit from price variations on different periods. In this scheme, the determination of prices for different periods of use is carried out in advance. Rates are discriminated by the electricity consumption profile, usually low prices during off-peak and high prices during peak. Energy-intensive customers can adjust their usage (load distribution) according to information on varying electricity tariffs provided by the utility in order to minimise energy bills [28].

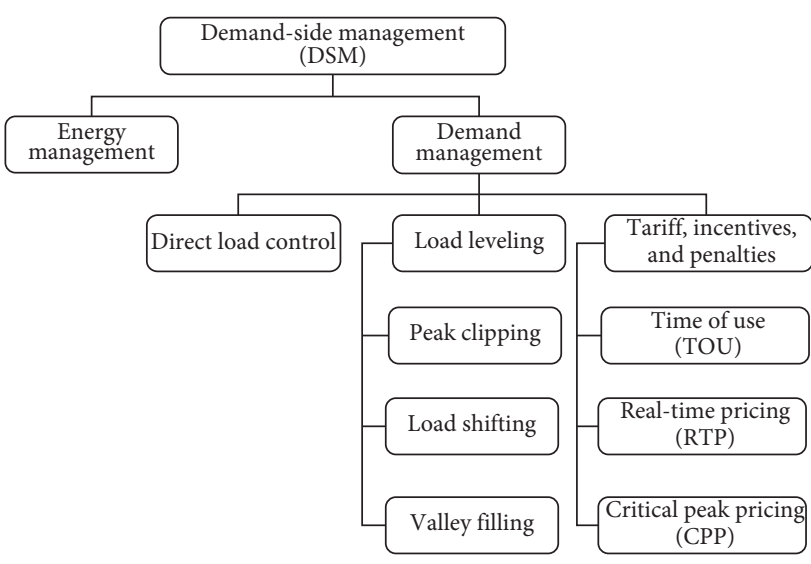

FIgURE 1: DSM programs.

The works of literature show that DRPs in electricity markets have predominantly been conducted in developed countries [29-31]. Despite the fast-growing electricity demand in developing countries, enough attention to DSM research has not been paid.

Jordehi et al. implemented the linear programming portfolio framework for microgrid scheduling for the Indian network. The linear model was a replacement of the nonlinear solutions which were found to be complicated in the implementations [32].

In Western Australia, it was observed that up to $2.95 \mathrm{kWh}$ energy was shifted to off-peak periods, enabling a total energy-saving of $3 \%$ per day. DSM is accounted for the saving through home energy management systems and fuzzy controller for monitoring of home appliances. Distributed energy management is a model developed for user and utilities in order to achieve energy management. Simulation results showed improvements when considering the efficiency and flexibility of the microgrid system [33].

On the other hand, by utilising intelligent demand response (DR) techniques, energy management was achieved through the use of Artificial Bee Colony algorithm and quasistatic technique. The method involved both the source and end-users aiming at improving the technical parameters such as load factor as well as cost minimisation. About $8.33 \%, 11.11 \%$, and $11.11 \%$ in cost reduction, peak reduction, and load factor improvements were reported, respectively [34]. Considering a community microgrid, a particle swarm optimisation model to explore the optimal operation of the battery by considering its charging/discharging rate was implemented [35]. The proposed algorithm reduced operational cost by $12 \%$ over a time horizon of 96 hours. In addition to that, Chauhan et al. proposed a new DSM scheme to solve the challenge of power loss during charging and discharging of a battery in an autonomous direct current (DC) microgrid. The proposed scheme aimed at using efficiently the energy generated from solar PV through reduction of energy demand during nonsunny hours by shifting controllable loads to sunny hours.

The results showed that customers achieved $32.62 \%$ in cost-saving with $36.36 \%$ and $25 \%$ savings in the cost of PV and battery, respectively. Furthermore, the proposed scheme 
reduced the battery bank charge/discharge rate resulting in increased battery life while keeping it healthy and cool $[14,36]$. Similarly, a DSM prototype was developed for an autonomous DC microgrid to reschedule the operation of deferrable loads to sunny hours. Results indicated an increase in the overall system efficiency as well as peak reduction [37].

The optimal cost of energy was achieved through both source and load management. Source management was performed by selecting the cheapest source to meet the demand during peak hours, while load management was through shifting the operation time of loads from peak to off-peak hours according to user preferences. The proposed scheme offered financial benefits to consumers as well as peak reduction [38].

In the same way, a system for grid energy optimisation was presented focusing on distributed energy resources for DSM and source-side management through selecting a cheaper or less emission source. Simulation results showed a reduction in electricity bill and peak demand [39]. An intelligent energy management system was designed for a gridtied microgrid to ensure load sharing by selecting the closest source to the load in order to reduce system losses and enhance its reliability and power quality. The idea exhibited essential features such as voltage stability and the ability to approach the ideal characteristics of the source through selecting the closest source to the load. The drawbacks such as inability to welcome new source or load which was observed in the other techniques reduced significantly [40].

However, the findings presented by authors in refs. [32-36, 38-40] did not comprehensively take into account the behaviour of customers. Customers' behaviours are expected to have a significant impact on electricity usage as they play a key role in decision making [41]. There are limited studies in sub-Saharan Africa that have comprehensively addressed the issues of customer behaviour in microgrids. Also, the existing DRPs and methodologies from developed countries cannot be directly applicable to most of the developing countries load profile due to low per capita energy consumption and even less flexible loads available [42].

Moreover, the unpredictable consumers' behaviour to price sensitivity may differ significantly between developed and developing countries $[43,44]$. The variation on customers' reaction to price change can be influenced by lifestyle, welfare, and even factors governing energy market [45]. The reasons mentioned above make it important to study the appropriate DSM methods that fit the targeted group. A limited number of research studies on DSM in sub-Saharan Africa should attract widespread attention of researchers in order to address challenges arising from traditional strategies such as load shedding. Therefore, in the present work, DSM has been proposed for isolated solar microgrid, and the proposed strategy takes into consideration the behaviour of customers using data collected from Ngurdoto solar microgrid, Arusha, Tanzania. We propose DSM based on incentives and price elasticity using the concept of price elasticity of demand and TOU [41]. Both LS and scheduled load reduction
(SLR) have been investigated. The proposed model presents the potential for balancing energy in the microgrid based on the customers' behaviour pattern. Simulations have been carried out on the real-time electricity consumption data of Ngurdoto solar microgrid in Arusha, Tanzania. The new contributions of the present work can be summarised as follows:

(i) We propose a DSM approach that can be adopted by utility sectors in sub-Saharan Africa to replace the traditional load shedding approach currently in use

(ii) Discussion and evaluation of the effect of different incentives on the proposed DSM strategy considering customers' behaviour are made

(iii) We demonstrate that consideration of customers' behaviours and incentives can effectively improve microgrid operation

(iv) The proposed DSM can resolve the mismatch between demand and supply for microgrids in developing countries through even distribution of power to avoid load shedding

\section{Materials and Methods}

2.1. The Case. Ngurdoto village found in the northern part of Tanzania is supplied with off-grid solar electricity. Customers are connected via electric poles, and each house has an individual smart meter for recording electricity usage, and the current pricing scheme used is a flat-rate tariff. When the demand is higher than the system can supply, the utility exerts a scheduled load shedding. High utilisation of solar electricity has prompted the need for DSM; therefore, this study explores other alternatives that can be implemented at Ngurdoto microgrid system. Simulations have been carried out to assess the possible improvements when considering customers' behaviour towards the reduction of stress on the microgrid system.

2.2. Data Collection. Ngurdoto solar microgrid $(7.5 \mathrm{~kW})$ is equipped with smart meters with a grid control and monitoring functions including data logging. For each smart meter, real-time data were recorded using a combination of remote sensing devices, data logger, and a remote PC. The data collection framework is shown in Figure 2. Collected demand data were analysed using Microsoft Excel and Matlab. The simulation was done using MATLAB R2018a software.

From the collected demand data of individual smart meters at different days of the year, some dissimilar types of total daily load profile are noted in Figure 3. In Figures 3(b), $3(\mathrm{~d})$, and 3(f), a typical and expected consumption pattern with the highest peak in the evening hours (1700-2200 hrs) is observed. Figures 3(a) and 3(c) also show the nearly expected load pattern of a village residential customer. However, an unusual pattern is observed in Figure 3(e) with the highest peaks in the late-night hours (0100-0500 hrs). From the survey conducted before data analysis, it was reported that due to the high usage of electricity, the utility 


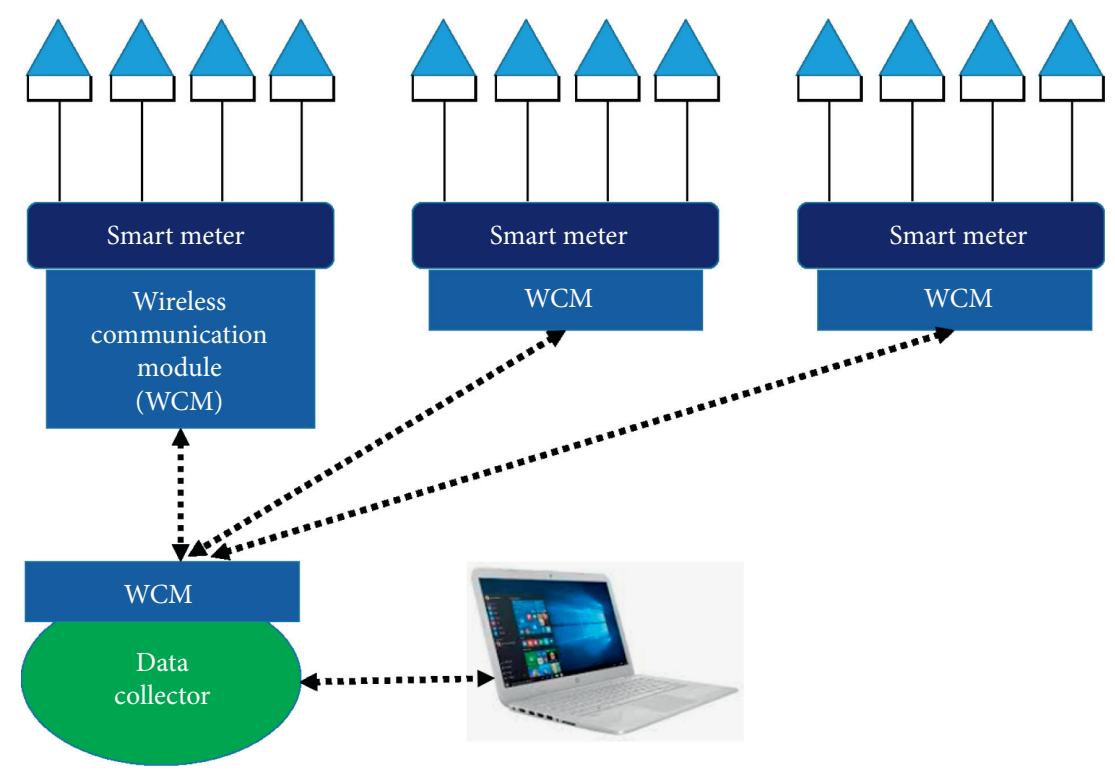

Figure 2: Data collection framework.

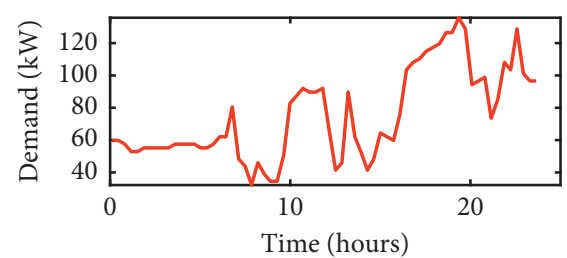

(a)

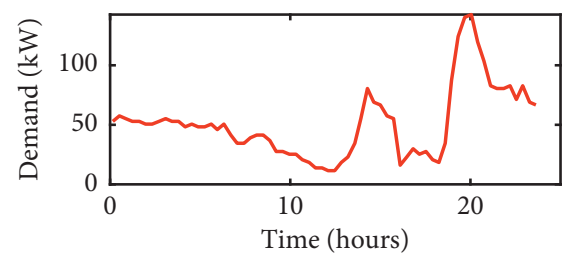

(d)

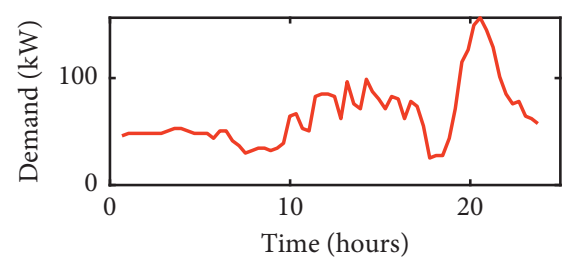

(b)

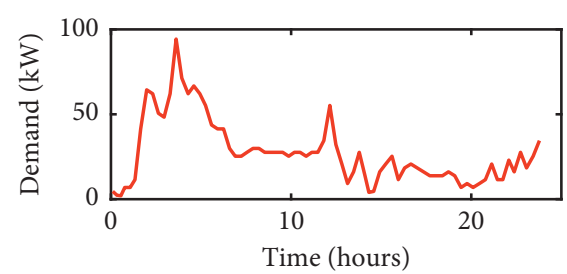

(e)

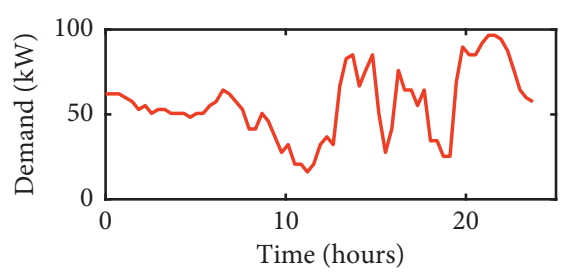

(c)

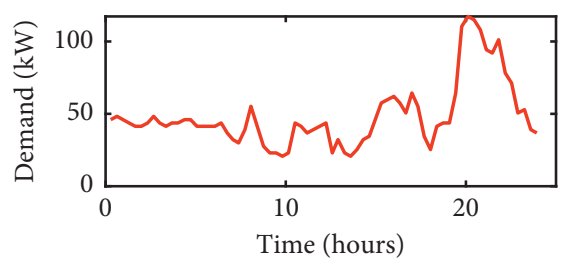

(f)

Figure 3: Different load profiles.

introduced a scheduled load shedding, and the utility advised customers to be vigilant to one another regarding electricity consumption in order to reduce peaks. As a result, a peak was observed at late night, indicating that people changed their usage pattern so that they are not noticeable. This scenario elicits the need for DSM that features customers' behaviours on electricity usage.

Load profile of weekend and weekdays is shown in Figure 4; higher consumptions are noted, expected pattern as more residents stay at their homes.

The high peaks observed pose a burden to the microgrid, and this shows a need for DSM incorporating the strategy that takes into account the change in behaviour. TOU pricing as a replacement to a flat-rate tariff for residential consumers of Ngurdoto, Tanzania, was thought as a solution to flatten the demand profile of consumer and utility altogether.
2.3. Mathematical Modeling. It is argued that the demand of almost all goods and services is a function of the price charged in a sense that the more the price, the less the demand and vice versa. Following different analysis of the scenarios for the considered customers in the presented study, we have adopted the model by Saeed et al. [46]. The model captures customers' behaviour through price elasticity parameters. The idea was first developed by Schweppe et al. [47], reported that a customer would react differently in adjusting demand following the spot prices. To reflect responsiveness between demand and price, a parameter known as price elasticity of demand derived through equation (1) is used: the model has been chosen as most of the developing countries' customers are price sensitive [48]:

$$
E(i, j)=\frac{(\Delta d(i) / d(i))}{(\Delta P(j) / P(j))} .
$$




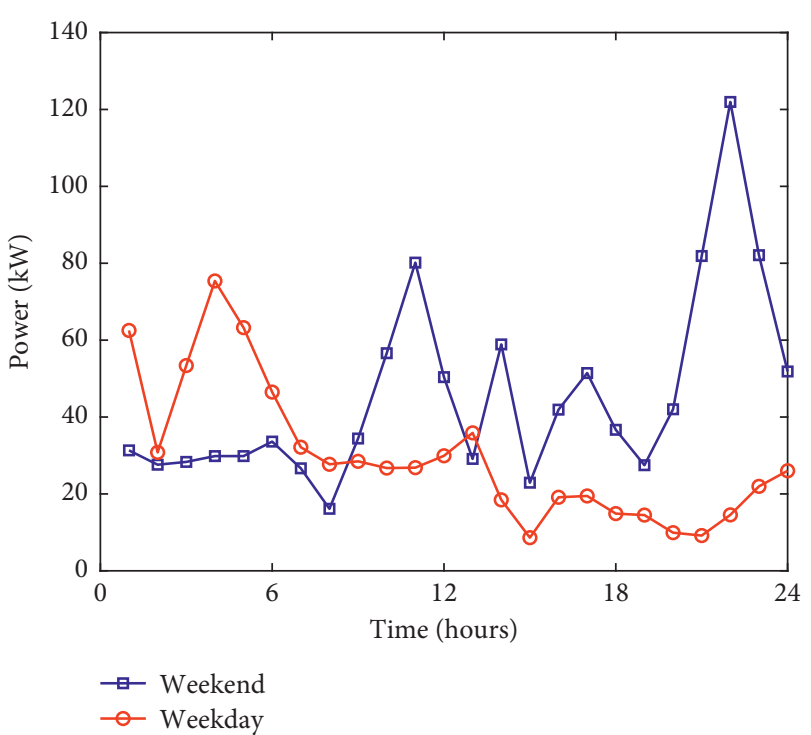

FIgURE 4: Weekend and weekday profile.

Price elasticity can be divided into two, namely, crosselasticity $(E(i, j))$ and self-elasticity when $(i=j),(E(i, i))$. Cross-elasticity measures the effect of the price of a specific time interval on electricity consumption during another time interval, whereas self-elasticity measures the demand reduction in a specified time interval due to the price of that interval $[26,49]$.

For $n$ number of time periods, the elasticity matrix can be written as follows:

$$
E=\left[\begin{array}{cccc}
E_{11} & E_{12} & . . & E_{1 n} \\
E_{21} & E_{22} & . . & E_{2 n} \\
: & : & : & : \\
E_{n 1} & E_{n 2} & . . & E_{n n}
\end{array}\right] .
$$

If a customer can reduce demand, he receives an incentive proportional to the change in demand achieved. The benefit gained can be quantified through the customer benefit function. The benefit received by the customer for the $i^{\text {th }}$ hour is as follows:

$$
B(d(i))=U(d(i))+P(\Delta d(i))-d(i) p(i) .
$$

The benefit is assumed to be in monetary values. The change in demand is calculated as follows:

$$
\Delta d(i)=d(i)-d_{0}(i)
$$

If $I(i)$ is an incentive paid to customers upon energy reduction at a given time, then the total incentive is calculated as follows:

$$
P \Delta d(i)=I(i) \times \Delta d(i) .
$$

The aim is to maximise individual benefit; therefore,

$$
\left(\frac{\partial B(d(i))}{\partial d(i)}\right)=0
$$

From the partial derivative of equation (6) by substituting in equation (5), the resulting expression is given by

$$
\left(\frac{\partial U(d(i))}{\partial d(i)}\right)=P(i)+I(i)
$$

The quadratic function is a reasonable model for customer benefit function [47], and the Taylor series expansion given in equation (7) is used to calculate the quadratic benefit function [50]. For the utility function, Taylor expansion can be written as follows:

$$
\begin{aligned}
U d(i)= & U\left(d_{0}(i)\right)+\left(\frac{\partial U\left(d_{0}(i)\right)}{\partial d(i)}\right) \times \Delta d(i)+\frac{1}{2} \\
& \times\left(\frac{\partial^{2} U\left(d_{0}(i)\right)}{\partial d^{2}(i)}\right) \times \Delta(d(i))^{2} .
\end{aligned}
$$

Assuming that the initial demand $d_{0}(i)$ before DSM is the optimal demand:

$$
\left(\frac{\partial U\left(d_{0}(i)\right)}{\partial d(i)}\right)=P_{0} .
$$

By substituting the derivative on equation (9) into equation (1), we obtain

$$
\left(\frac{\partial^{2} U\left(d_{0}(i)\right)}{\partial d^{2}(i)}\right)=\left(\frac{\partial P}{\partial d}\right)=\left(\frac{1}{E}\right) \times\left(\frac{P_{0}}{d_{0}}\right) .
$$

By substituting equation (9) and equation (10) in the Taylor expansion in equation (8) and rewriting the equation, we obtain the customer consumption as follows:

$$
d(i)=d_{0}(i) \times\left[1+\left(\frac{E(i) \times\left(P(i)-P_{0}(i)+I(i)\right)}{P_{0}(i)}\right)\right] \text {. }
$$

The total DR model obtained by combining the crossand self-elasticity can be written as follows:

$$
\begin{aligned}
d(i)= & d_{0}(i)+E(i) \times\left(\frac{d_{0}(i)}{P_{0}(i)}\right) \times\left(P(i)-P_{0}(i)+I(i)\right) \\
& +\sum_{\substack{j=1 \\
j \neq 1}}^{24} E(i, j) \times\left(\frac{d_{0}(i)}{P_{0}(j)}\right) \times\left(P(j)-P_{0}(j)+I(j)\right) .
\end{aligned}
$$

The change in demand in equation (12) represents both incentive and price responsive demand.

\section{Results and Discussion}

3.1. Numerical Studies. The load profile of the Tanzanian microgrid of $1725 \mathrm{~kW}$ peak capacity located in Arusha on 25 March 2019 (Figure 5) was studied and analysed. The selection was made considering the highest peak day. The load profile is subdivided into three main periods, namely, peak 


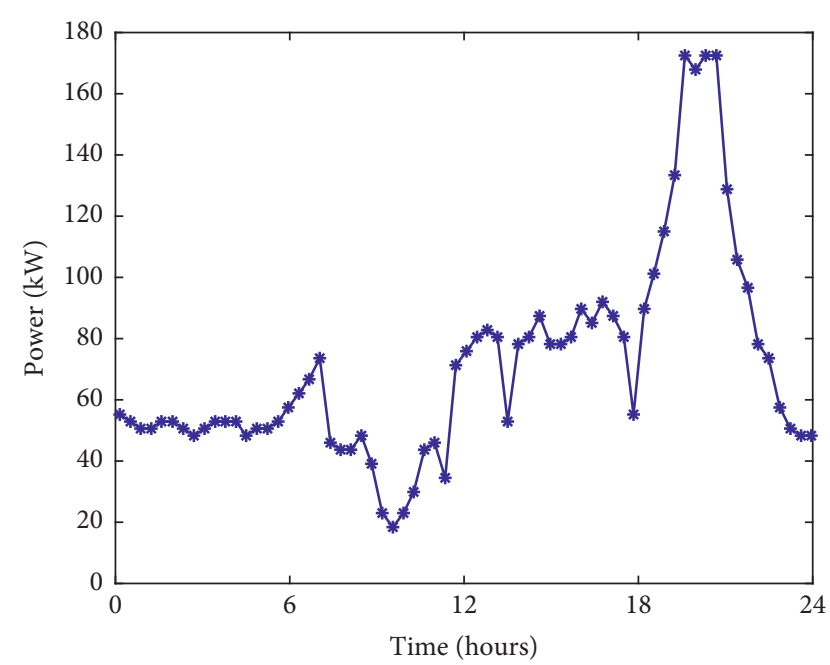

FIGURE 5: Baseload profile for 24 hours recorded on a peak day (24/ 03/2019).

period (1800-2200 hrs), off-peak period (0100-0700 hrs), and low periods (0700-1800 hrs) and (2200-0100 hrs).

The current electricity prices used in the system are a flatrate tariff whereby customers pay a fixed amount of money through the time intervals of the day. This work employed TOU prices to implement the two DRPs SLR and LS. The prices were considered according to Zhao et al., who calculated TOU prices for different time intervals [51]. For SLR, only high prices were charged during peak hours and kept constant in off-peak and low-peak intervals (Figure 6), while for LS, high and low prices were charged during peak and offpeak hours, respectively. Price elasticity values listed in Tables 1 and 2 are used to illustrate customer's response towards an increase in price. Such price elasticities are modified to reflect rural developing countries' microgrid system conditions. For SLR, self-elasticity during peak hours is taken as 0.1 , which means that a $100 \%$ increase in price results in a $10 \%$ load reduction. In the same table, the elasticities for off-peak and low intervals are nearly approximated to zero, implying that there is no significant response to demand reduction due to insignificant variation in prices. LS results are summarised in Table 3. A decrease in demand during peak hours with an increase in demand in off-peak hours was observed. One may argue that the shift observed is due to high prices during peak and low prices during off-peak.

3.2. Base Case. The base case without application of a demand-side strategy for the actual load profile is presented in the first rows of Tables 3 and 4 . The tables explain values as a result of the numerical calculation of demand and prices before and after the implementation of DSM strategies. The base profile shows the maximum peak demand of $4754.1 \mathrm{~kW}$ and the price of 108.62 USD is paid by the customers. The results are based on flat-rate tariff without the provision of incentives and TOU pricing schemes. The indices before the implementation of DRPs are expected to improve after LS and SLR. The following sections discuss the effects of elasticity and incentives on LS and SLR.

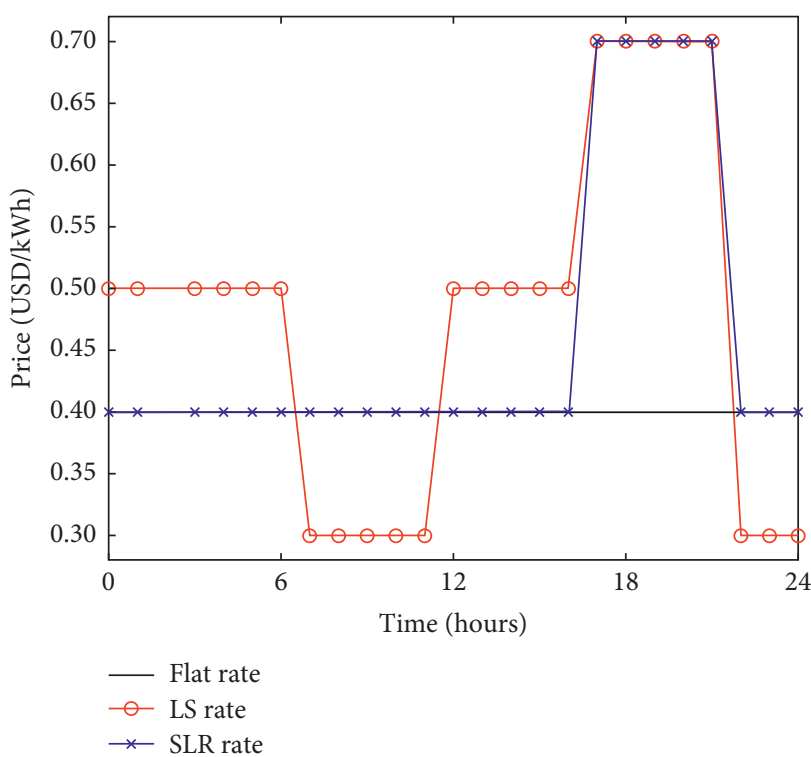

FIGURE 6: Different TOU pricing schemes for the implementation of DSM programs.

TABLE 1: Self-elasticity and cross-elasticity factors for SLR.

\begin{tabular}{lccc}
\hline & Low-load & Off-peak & Peak \\
\hline Low-load & -0.0100 & 0.0016 & 0.0012 \\
Off-peak & 0.0016 & -0.0100 & 0.0029 \\
Peak & 0.0012 & 0.0029 & -0.1000 \\
\hline
\end{tabular}

TABle 2: Self- and cross-elasticity factors for LS.

\begin{tabular}{lccc}
\hline & Low-load & Off-peak & Peak \\
\hline Low-load & -0.010 & 0.002 & 0.001 \\
Off-peak & 0.014 & -0.010 & 0.293 \\
Peak & 0.013 & 0.018 & -0.100 \\
\hline
\end{tabular}

3.2.1. LS. For LS DR program, highest prices are applied to almost $21 \%$ of all hours representing peak periods in a day. For the remaining $79 \%$, the utility charges low and medium prices to encourage customers to shift their loads. As can be observed from Figure 7 and Table 3, this program resulted in $4.87 \%$ energy-saving and approximately $15.8 \%$ moneysaving; the effect of elasticity alone without any incentive was represented by case 1 . With an increase in incentives, more loads were shifted to off-peak hours, which resulted in $19.23 \%$ money-saving with the highest incentive value of 250 cents/kWh. Case 6 represents the assumption that no load has been shut down instead shifted to hours of off-peak times, which achieved no saving in energy; however, savings in terms of money was $19.22 \%$ since electricity usage was charged at a low price. In case 7 , the customer saving is negative $(-6.4 \mathrm{~kW})$, which means that the customer's energy loss is equal to $0.13 \%$; this implies that the customer increased energy consumption. From these observations, we note that LS might result in an increase in peaks to some other off-peak periods leading to energy wastage when incentives values are not logically chosen, and this is in line 
TABLE 3: Numerical results on energy and cost-saving, a case of LS.

\begin{tabular}{|c|c|c|c|c|c|c|c|}
\hline Case & Incentive (cent/kWh) & Demand after $(\mathrm{kW})$ & Saving $(\mathrm{kW})$ & \% saving $(\mathrm{kW})$ & Cost after (USD) & Saving (USD) & \% saving \\
\hline Base & 0 & 4754.1 & 0.0 & 0.00 & 108.62 & 0.00 & 0.00 \\
\hline 1 & 0 & 4522.8 & 231.3 & 4.87 & 91.46 & 17.16 & 15.80 \\
\hline 2 & 50 & 4570.4 & 183.7 & 3.86 & 90.15 & 18.47 & 17.01 \\
\hline 3 & 100 & 4617.9 & 136.2 & 2.86 & 89.12 & 19.50 & 17.96 \\
\hline 4 & 150 & 4665.4 & 88.7 & 1.87 & 88.37 & 20.25 & 18.64 \\
\hline 5 & 200 & 4713.0 & 41.1 & 0.86 & 87.91 & 20.71 & 19.07 \\
\hline 6 & 243 & 4754.1 & 0.0 & 0.00 & 87.74 & 20.88 & 19.22 \\
\hline 7 & 250 & 4760.5 & -6.4 & -0.13 & 87.73 & 20.89 & 19.23 \\
\hline
\end{tabular}

TABLe 4: Numerical results on energy- and cost-saving, a case of SLR.

\begin{tabular}{|c|c|c|c|c|c|c|c|}
\hline Case & Incentives (cent/kWh) & Demand after $(\mathrm{kW})$ & Saving $(\mathrm{kW})$ & $\%$ saving $(\mathrm{kW})$ & Cost after (USD) & Saving (USD) & $\%$ saving \\
\hline Base & 0 & 4754.1 & 0.0 & 0.00 & 108.62 & 0.00 & 0.00 \\
\hline 1 & 0 & 4622.8 & 131.3 & 2.76 & 96.39 & 12.23 & 11.26 \\
\hline 2 & 50 & 4467.2 & 286.9 & 6.03 & 85.91 & 22.71 & 20.91 \\
\hline 3 & 100 & 4311.6 & 442.5 & 9.31 & 76.48 & 32.14 & 29.59 \\
\hline 4 & 150 & 4156.0 & 598.1 & 12.58 & 68.11 & 42.51 & 37.29 \\
\hline 5 & 200 & 4000.4 & 753.7 & 15.85 & 60.79 & 47.83 & 44.03 \\
\hline 6 & 243 & 3865.8 & 888.3 & 18.68 & 55.31 & 53.31 & 49.08 \\
\hline 7 & 250 & 3844.8 & 909.3 & 19.13 & 54.52 & 54.10 & 49.80 \\
\hline
\end{tabular}

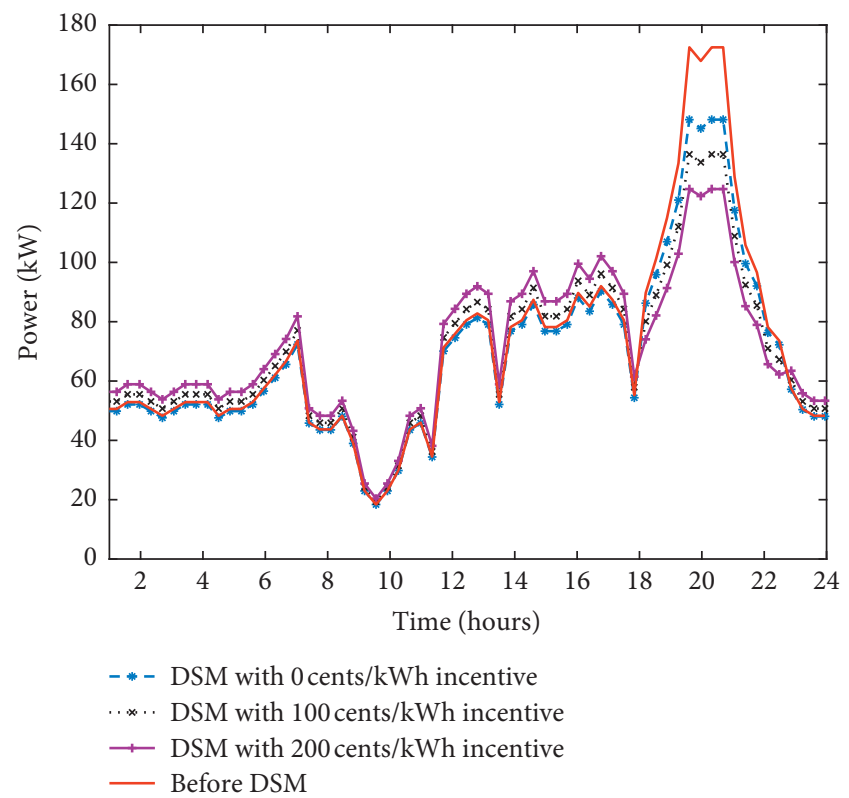

Figure 7: Load profile before and after implementation of LS DSM with different values of incentives.

with Ref. [19, 52], which is further supported by Moghaddam et al. [53], where an increase of $0.11 \%$ in energy usage was achieved through TOU at a factor of 0.5 which represented the will of the customer to shift their loads.

3.2.2. SLR. In this program, the TOU program and incentives provision is implemented in $18-22$ hours. The interest is to reduce load during peak hours while preserving the same load during regular hours. The results from Figure 8 and Table 4 show improvement in load profile characteristics and the customer cost is reduced. As it is

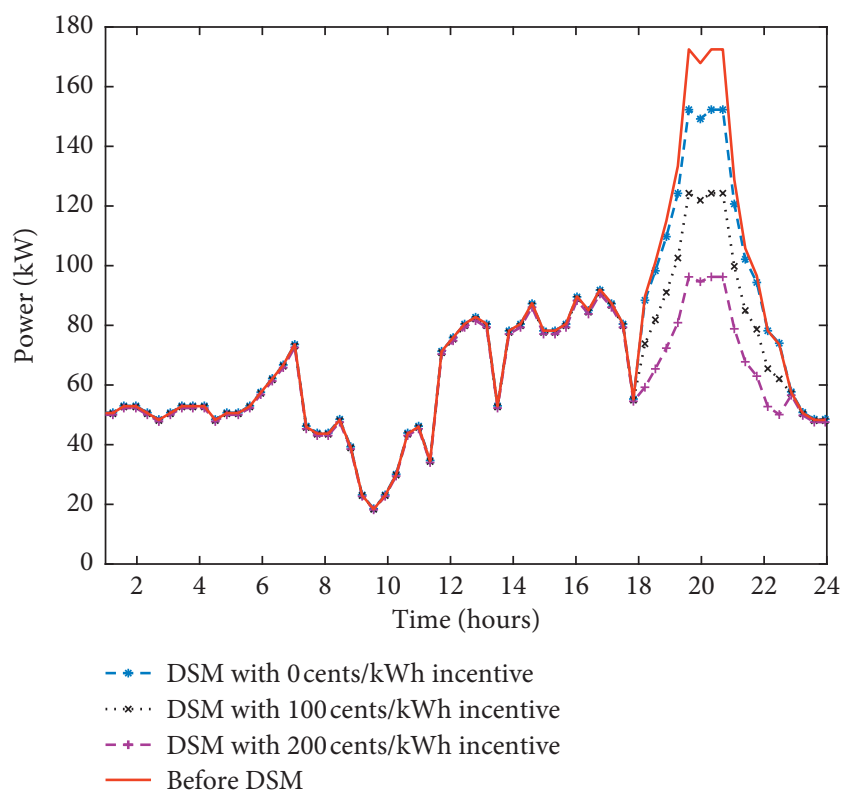

FIgURE 8: Load profile before and after implementation of SLR DSM with different values of incentives.

shown in Figure 8 , with an increase in incentive value, a more flat profile is achieved. The program attained a maximum of $909.30 \mathrm{~kW}$ and $54.1 \mathrm{USD}$ at an incentive value of 250 cents/kWh. There is an indication that with the SLR program, the increase in incentives results in both energyand cost-saving, which shows a direct relationship between incentive, cost, and energy.

3.3. Programs Comparison. The SLR and LS have been analysed; the results show that LS gives the least percentage in both energy-saving and cost as observed from Figures 9 


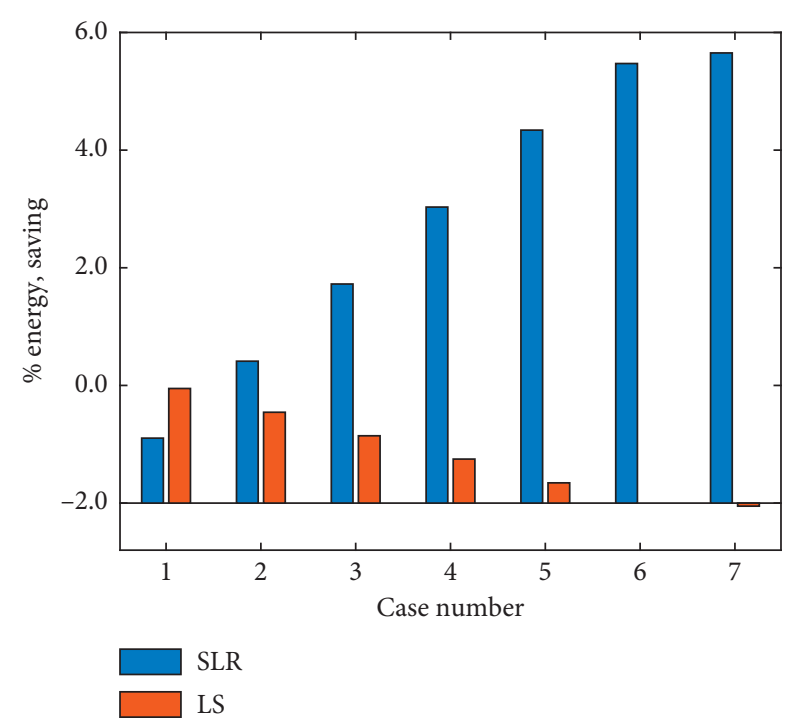

FIGURE 9: SLR and LS on energy-saving.

and 10. One can argue that there are possibilities of increasing both energy-saving through incentives and customers' flexibility since they can take advantages of low prices during off-peak hours. Also, an inverse relationship exists between energy-saving and cost-saving in the LS strategy. SLR gives both energy-saving and cost-saving, and from Figure 9, SLR results in about 17\% energy-saving at 243 cents/kWh incentives while for the same value of incentive in LS, no energy-saving was achieved. Likewise, Figure 10 shows the effect of incentives on cost-savings which explains the customer behaviour on energy consumption when incentivised.

We have demonstrated that, with SLR, both energy- and cost-saving are achieved, although the question comes regarding whether the priority is energy-saving or cost-saving and also the comfort of both customers and utility. Therefore, savings in both energy and cost is perceived differently when considering the utility and the customer side; that is why Moghaddam et al. discussed the priority of programs considering utility and customer point of view [53].

3.4. The Impacts of LS and SLR on the Technical and Economical Indices. The impacts on the technical and economical indices after the application of DSM with different values of incentives are given in Tables 5 and 6 . According to Table 5, which represents DSM through LS, the increase in incentive value is proportional to the percentage in peak reduction. Without the provision of incentive, peak reduced by $14.12 \%$ due to the influence of market elasticity set by the utility. In this scenario, one may suppose that customers reacted as a result of high prices set by the utility and hence decide to reduce their consumption at that time. The main reasons for peak reduction, in this case, are customer welfare and price elasticity as the authors demonstrated it in Ref. [48]. The remaining amount of load has been shifted to other off-peak hours due to the effect of cross-elasticity [19].

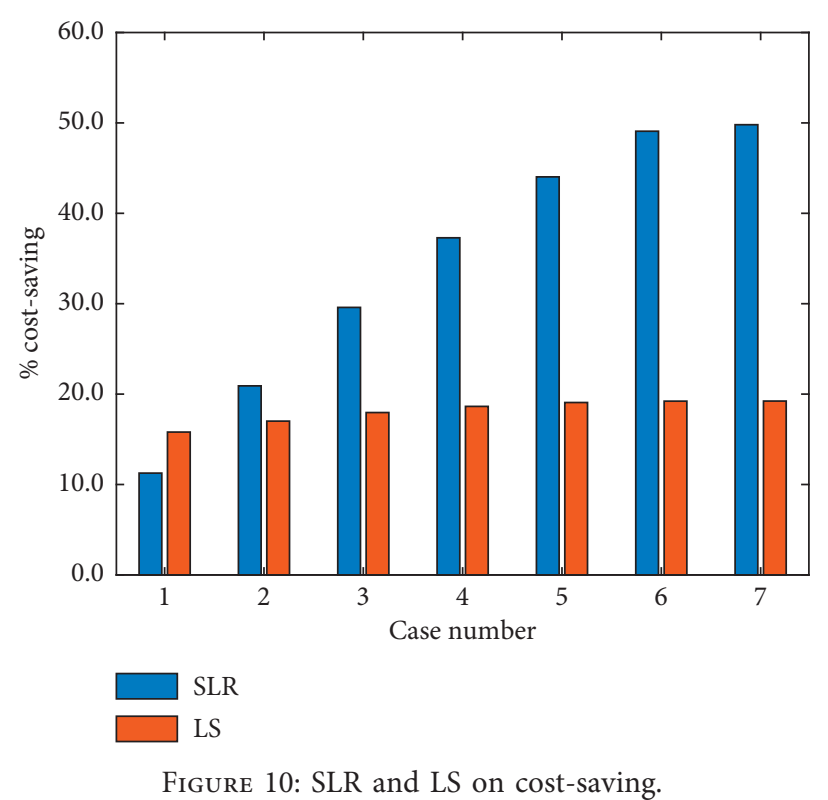

Likewise, a significant improvement in load factor up to $18.85 \%$ has been observed. Customers can save up to 20.89 USD although a decrease in utility revenue of about 22 USD is noted when a higher amount of incentive is provided.

For the case of SLR shown in Table 6, the amount of peak reduction is in the range of $11.71-47.69 \%$ due to DSM and incentives. An increase in load factor is observed with a maximum of 54.1 USD customer profit at 250 cents $/ \mathrm{kWh}$ incentive. Similarly, the utility revenue is on the decreasing trend with an increase in incentive values.

In Figures 11-13, the impact of peak reduction, power factor improvements, and utility revenue has been assessed for LS and SLR DRPs. At 0 cent $/ \mathrm{kWh}$ incentive, SLR shows a $2.49 \%$ lesser peak reduction compared to LS, indicating that customers' elasticity to load decrement is more when they have an alternative of shifting loads to other periods of the day. Through SLR, a more significant improvement of load factor is noted when compared to LS. However, utilities are prone to lose more revenue when selecting SLR DSM in comparison with LS. Customers are expected to save more in SLR compared to LS although their comfort is compromised due to less flexibility of shifting loads during peak hours. At low incentive values, LS has a better power factor compared to SLR, while SLR outweighs LS when higher values of incentives are provided. Utility revenue decreases with an increase in incentives in SLR while LS shows a slighter decrease in utility revenue.

It can be concluded that incentives play an important role in preventing utility owners from suffering the cost of load shedding in microgrid operations [19]; however, when there is no proper selection of the incentive value, the utility may suffer from a high loss in revenue. It has been proven that, with an increase in price elasticity of customers, a utility can generate more profit since incentive payments will be few [54]. Therefore, for successful DRPs, it is essential to analyse the benefits incurred to both actors such as 
TABLE 5: Result summary of different technical and economical indices before and after applying LS DSM at different incentive values.

\begin{tabular}{|c|c|c|c|c|c|c|c|c|}
\hline \multirow{2}{*}{ Index } & \multirow{2}{*}{ Without DSM } & \multicolumn{7}{|c|}{ With DSM at different incentive values (cents/kWh) } \\
\hline & & 0 & 50 & 100 & 150 & 200 & 243 & 250 \\
\hline$\%$ peak reduction & 0 & 14.12 & 17.52 & 20.91 & 24.31 & 27.70 & 30.62 & 31.09 \\
\hline$\%$ load factor & 41.13 & 45.94 & 48.29 & 50.83 & 53.61 & 56.64 & 59.49 & 59.98 \\
\hline Customer bill (USD) & 108.62 & 91.46 & 90.15 & 89.12 & 88.37 & 87.91 & 87.74 & 87.73 \\
\hline Customer profit (USD) & 0 & 17.16 & 18.47 & 19.5 & 20.25 & 20.71 & 20.88 & 20.89 \\
\hline Utility revenue (USD) & 108.62 & 91.46 & 90.15 & 89.12 & 88.37 & 87.91 & 87.74 & 87.73 \\
\hline
\end{tabular}

TABLE 6: Result summary of different indices before and after applying SLR DSM at different incentive values.

\begin{tabular}{lcccccrrr}
\hline \multirow{2}{*}{ Index } & \multirow{2}{*}{ Without DSM } & \multicolumn{3}{c}{ With DSM at different incentive values (cents/kWh) } \\
& & 0 & 50 & 100 & 150 & 200 & 243 & 250 \\
\hline \% peak reduction & 0 & 11.71 & 19.84 & 27.96 & 36.08 & 44.20 & 47.67 \\
\% load factor & 41.13 & 45.54 & 48.62 & 52.39 & 57.12 & 63.23 & 65.38 & 65.69 \\
Customer bill (USD) & 108.62 & 96.39 & 85.91 & 76.48 & 68.11 & 60.79 & 55.31 & 54.52 \\
Customer profit (USD) & 0 & 12.23 & 22.71 & 32.14 & 42.51 & 47.83 & 53.31 & 54.10 \\
Utility revenue (USD) & 108.62 & 96.39 & 85.91 & 76.48 & 68.11 & 60.79 & 55.31 & 54.52 \\
\hline
\end{tabular}

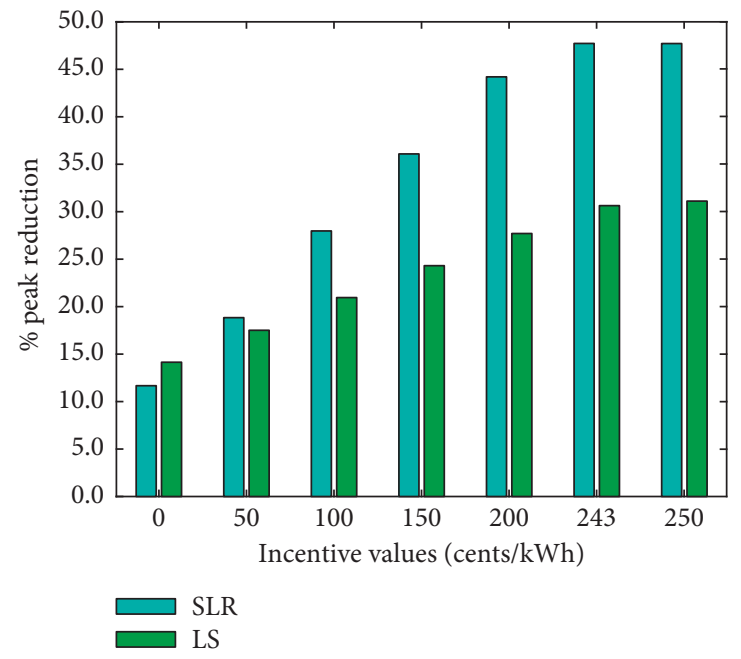

FIgURE 11: Percentage peak reduction after implementation of LS and SLR DSM programs.

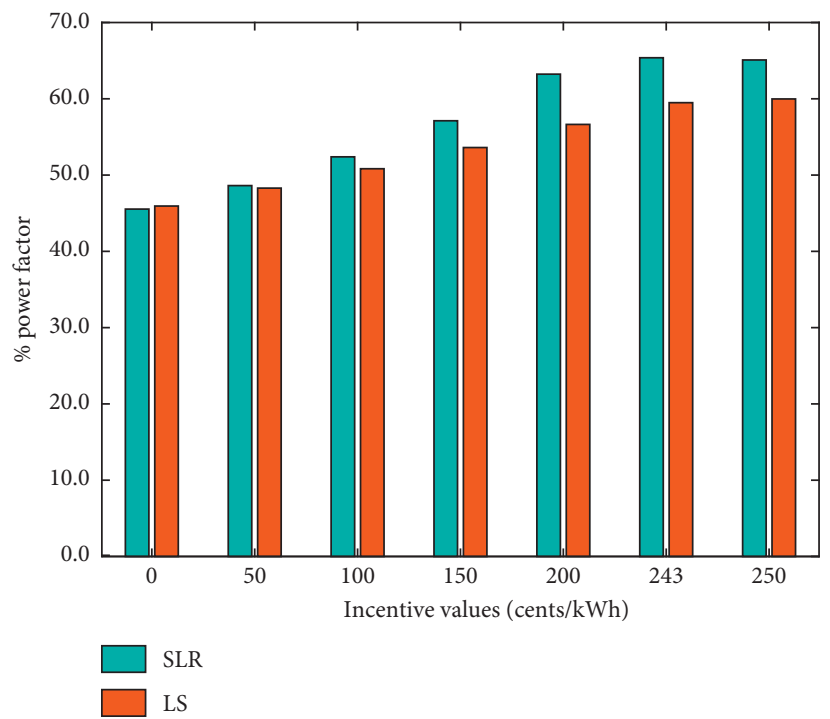

FIGURE 12: Percentage power factor after implementation of LS and SLR DSM programs. 


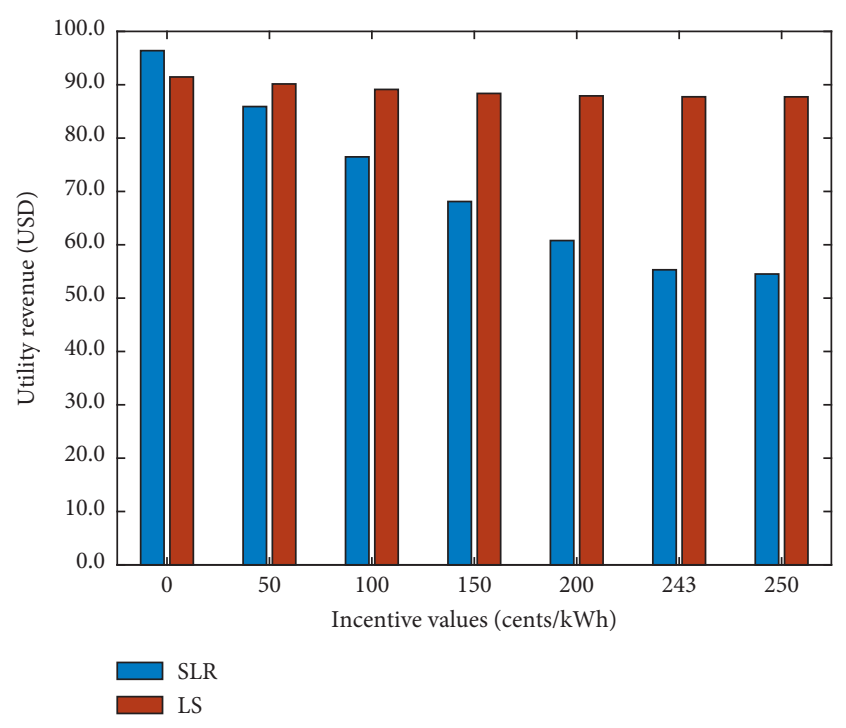

FIGURE 13: Utility revenue after implementation of LS and SLR DSM programs.

customer, utility companies, regulators, and community, for their mutual benefit as discussed in Ref. [55].

\section{Conclusion}

In this paper, the effect of time-of-use pricing and incentives has been investigated by using the concept of price elasticity of demand. This model presents the potentials of improving customer satisfaction as well as improving the load profile characteristics. We observe that both LS and SLR are appropriate strategies for peak reduction. However, this is dependent on customer's interest whether to have more savings for both cost and energy or sacrificing one of them. This situation is always a subjective matter as customer utilisation level also depends on the benefit received from electricity usage. Based on the results, about $19 \% \mathrm{~kW}$ and 20.89 USD can be saved through LS with $18.85 \%$ improvement in power factor. SLR improved the power factor by $23.96 \%$, with cost-saving of 54.1 USD although utility revenue dropped significantly. Therefore, considering the two strategies of demand-side management, utilities can efficiently decide which one to implement in their power generation units. With this study, utilities can be able to solve the deficiency of energy, especially during peak hours through shifting the loads in time or filling the valleys when supply is higher than the demand. It can further increase the renewable energy source reliability and efficiency, maximise electricity consumption during a proper time, and cut down investment cost with a reduced payback period. However, factors such as the number of households and the size of houses may also affect customer behaviour on electricity consumption which should be further investigated.

\section{Abbreviations}

DSM: Demand-side management

TOU: $\quad$ Time of use

$\begin{array}{ll}\text { RTP: } & \text { Real-time pricing } \\ \text { DLC: } & \text { Direct load control } \\ \text { SLR: } & \text { Scheduled load reduction } \\ \text { CPP: } & \text { Critical peak pricing } \\ \text { DR: } & \text { Demand response } \\ \text { DRPs: } & \text { Demand response programs } \\ \text { LS: } & \text { Load shifting } \\ \text { MATLAB: } & \text { Matrix laboratory } \\ \text { WCM: } & \text { Wireless communication module } \\ E: & \text { Price elasticity } \\ P_{0}: & \text { Initial price } \\ d_{0}: & \text { Initial demand } \\ \partial d: & \text { Change in demand } \\ \partial p: & \text { Change in price } \\ B(d(i)): & \text { Benefit function } \\ U(d(i)): & \text { Utility function } \\ P(\Delta d(i)): & \text { Total incentive } \\ I(i): & \text { An incentive for demand reduction } \\ E_{i i}: & \text { Self-elasticity } \\ E_{i j}: & \text { Cross-elasticity } \\ i, j: & \text { Time periods } \\ \text { DC: } & \text { Direct current. } \\ & \end{array}$

\section{Data Availability}

The data used to support the study will be provided upon request to the corresponding author.

\section{Conflicts of Interest}

The authors declare that they have no conflicts of interest.

\section{Authors' Contributions}

This paper was a collaborative effort between the authors. The authors contributed collectively from the idea development to manuscript preparation.

\section{Acknowledgments}

The authors express their heartfelt gratitude to the Nelson Mandela African Institution of Science and Technology (NM-AIST) for facilitating this research; the authors are grateful to the Water Infrastructure and Sustainable Energy Futures (WISE-Futures) for sponsoring this work. The authors are also grateful to everyone for their kind assistance, particularly Mr. Geradius Deogratias and Dr. Daniel Ngondya.

\section{References}

[1] P. Ravibabu, A. Praveen, C. V. Chandra, P. R. Reddy, and M. K. R. Teja, "An approach of DSM techniques for domestic load management using fuzzy logic," in Proceedings of the 2009 IEEE International Conference on Fuzzy Systems, pp. 1303-1307, Jeju Island, South Korea, August 2009.

[2] E. Hartvigsson, J. Ehnberg, E. Ahlgren, and S. Molander, "Assessment of load profiles in minigrids: a case in Tanzania," in Proceedings of the 2015 50th International Universities 
Power Engineering Conference (UPEC), pp. 1-5, Stoke on Trent, UK, September 2015.

[3] S. Choudhury, A. Parida, R. M. Pant, and S. Chatterjee, "GIS augmented computational intelligence technique for rural cluster electrification through prioritized site selection of micro-hydro power generation system," Renewable Energy, vol. 142, pp. 487-496, 2019.

[4] URT, "2012 Population and housing census," National Bureau of Statistics and Office of Chief Government Statistician. NBS. Dar es Salaam, pp. 1-264, 2013.

[5] A. Groth, "Socio-economic impacts of rural electrification in Tanzania," International Journal of Sustainable Energy Planning and Management, vol. 21, 2019.

[6] E. Mengelkamp, J. Gärttner, K. Rock, S. Kessler, L. Orsini, and C. Weinhardt, "Designing microgrid energy markets: a case study: the brooklyn microgrid," Applied Energy, vol. 210, pp. 870-880, 2018.

[7] R. K. Chauhan, F. Gonzalez-Longatt, B. S. Rajpurohit, and S. N. Singh, "DC microgrid in residential buildings," in $D C$ Distribution Systems and Microgrids, vol. 115, pp. 367-387, Institution of Engineering and Technology, London, UK, 2018.

[8] Y. Yoldaş, A. Önen, S. Muyeen, A. V. Vasilakos, and İ. Alan, "Enhancing smart grid with microgrids: challenges and opportunities," Renewable and Sustainable Energy Reviews, vol. 72, pp. 205-214, 2017.

[9] A. Pueyo, M. Carreras, and G. Ngoo, "Exploring the linkages between energy, gender, and enterprise: evidence from Tanzania," World Development, vol. 128, Article ID 104840, 2020.

[10] International Energy Agency, World Energy Outlook 2012, International Energy Agency, vol. 2013, Tokyo, Japan, 2012.

[11] C. K. Sao and P. W. Lehn, "Control and power management of converter fed microgrids," IEEE Transactions on Power Systems, vol. 23, no. 3, pp. 1088-1098, 2008.

[12] M. Malekzadeh, A. Khosravi, and M. Tavan, "Immersion and invariance-based filtered transformation with application to estimator design for a class of DC-DC converters," Transactions of the Institute of Measurement and Control, vol. 41, no. 5, pp. 1323-1330, 2019.

[13] A. A. Zaidi, F. Kupzog, T. Zia, and P. Palensky, "Load recognition for automated demand response in microgrids," in Proceedings of the IECON 2010-36th Annual Conference on IEEE Industrial Electronics Society, pp. 2442-2447, Glendale, AZ, USA, November 2010.

[14] R. K. Chauhan, C. Phurailatpam, B. Rajpurohit, F. GonzalezLongatt, and S. Singh, "Demand-side management system for autonomous DC microgrid for building," Technology and Economics of Smart Grids Sustainable Energy, vol. 2, no. 1, p. 4, 2017.

[15] S. Mišák, J. Stuchlý, J. Platoš, and P. Krömer, "A heuristic approach to active demand side management in off-grid systems operated in a smart-grid environment," Energy and Buildings, vol. 96, pp. 272-284, 2015.

[16] J. A. Laghari, H. Mokhlis, A. H. A. Bakar, and H. Mohamad, "Application of computational intelligence techniques for load shedding in power systems: a review," Energy Conversion and Management, vol. 75, pp. 130-140, 2013.

[17] J. P. Barton and D. G. Infield, "Energy storage and its use with intermittent renewable energy," IEEE Transactions on Energy Conversion, vol. 19, no. 2, pp. 441-448, 2004.

[18] C. Cecati, C. Citro, and P. Siano, "Combined operations of renewable energy systems and responsive demand in a smart grid," IEEE Transactions on Sustainable Energy, vol. 2, no. 4, pp. 468-476, 2011.

[19] M. H. Imani, P. Niknejad, and M. Barzegaran, "The impact of customers' participation level and various incentive values on implementing emergency demand response program in microgrid operation," International Journal of Electrical Power Energy Systems, vol. 96, pp. 114-125, 2018.

[20] M. M. Eissa, "Demand side management program evaluation based on industrial and commercial field data," Energy Policy, vol. 39, no. 10, pp. 5961-5969, 2011.

[21] J. Torriti, "Price-based demand side management: assessing the impacts of time-of-use tariffs on residential electricity demand and peak shifting in Northern Italy," Energy, vol. 44, no. 1, pp. 576-583, 2012.

[22] J. Ma, J. Deng, L. Song, and Z. Han, "Incentive mechanism for demand side management in smart grid using auction," IEEE Transactions on Smart Grid, vol. 5, no. 3, pp. 1379-1388, 2014.

[23] Q. B. Dam, S. Mohagheghi, and J. Stoupis, "Intelligent demand response scheme for customer side load management," in Proceedings of the IEEE Energy 2030 Conference, pp. 1-7, Atlanta, GA, USA, November 2008.

[24] I. K. Maharjan, Demand Side Management: Load Management, Load Profiling, Load Shifting, Residential and Industrial Consumer, Energy Audit, Reliability, Urban, Semi-urban and Rural Setting, LAP Lambert Academic Publishing, Saarbrücken, Germany, 2010.

[25] P. Warren, "A review of demand-side management policy in the UK," Renewable and Sustainable Energy Reviews, vol. 29, pp. 941-951, 2014.

[26] M. H. Albadi and E. F. El-Saadany, "A summary of demand response in electricity markets," Electric Power Systems Research, vol. 78, no. 11, pp. 1989-1996, 2008.

[27] T. Logenthiran, D. Srinivasan, and T. Z. Shun, "Demand side management in smart grid using heuristic optimization," IEEE Transactions on Smart Grid, vol. 3, no. 3, pp. 1244-1252, 2012.

[28] A. Allman and Q. Zhang, "Distributed cooperative industrial demand response," Journal of Process Control, vol. 86, pp. 81-93, 2020.

[29] M. Paulus and F. Borggrefe, "The potential of demand-side management in energy-intensive industries for electricity markets in Germany," Applied Energy, vol. 88, no. 2, pp. 432-441, 2011.

[30] K. Herter, P. McAuliffe, and A. Rosenfeld, "An exploratory analysis of California residential customer response to critical peak pricing of electricity," Energy, vol. 32, no. 1, pp. 25-34, 2007.

[31] D. Kuiken and H. F. Más, "Integrating demand side management into EU electricity distribution system operation: a Dutch example," Energy Policy, vol. 129, pp. 153-160, 2019.

[32] A. R. Jordehi, "Optimisation of demand response in electric power systems, a review," Renewable and Sustainable Energy Reviews, vol. 103, pp. 308-319, 2019.

[33] M.-f. He, F.-x. Zhang, Y. Huang, J. Chen, J. Wang, and R. Wang, "A distributed demand side energy management algorithm for smart grid," Energies, vol. 12, no. 3, p. 426, 2019.

[34] H. B. Yamchi, H. Shahsavari, N. T. Kalantari, A. Safari, and M. Farrokhifar, "A cost-efficient application of different battery energy storage technologies in microgrids considering load uncertainty," Journal of Energy Storage, vol. 22, pp. 1726, 2019.

[35] M. A. Hossain, H. R. Pota, S. Squartini, and A. F. Abdou, "Modified PSO algorithm for real-time energy management 
in grid-connected microgrids," Renewable Energy, vol. 136, pp. 746-757, 2019.

[36] C. Phurailatpam, R. Chauhan, B. S. Rajpurohit, F. M. G. Longatt, and S. N. Singh, "Demand Side Management System for Future Buildings," in Proceedings of the 2016 First International Conference on Sustainable Green Buildings and Communities (SGBC), pp. 1-6, Chennai, India, December 2016.

[37] R. K. Chauhan and K. Chauhan, Impact of Demand-Side Management System in Autonomous DC Microgrid Decision Making Applications In Modern Power Systems, pp. 389-410, Elsevier, Amsterdam, Netherlands, 2020.

[38] R. K. Chauhan, B. S. Rajpurohit, L. Wang, F. M. G. Longatt, and S. N. Singh, "Real time energy management system for smart buildings to minimize the electricity bill," International Journal of Emerging Electric Power Systems, vol. 18, no. 3, 2017.

[39] K. Chauhan and R. Chauhan, "Optimization of grid energy using demand and source side management for DC microgrid," Journal of Renewable and Sustainable Energy, vol. 9, no. 3, Article ID 035101, 2017.

[40] R. K. Chauhan and K. Chauhan, Management of Renewable Energy Source and Battery Bank for Power Losses Optimization Smart Power Distribution Systems, pp. 299-320, Elsevier, Amsterdam, Netherlands, 2019.

[41] S. Mohajeryami, I. N. Moghaddam, M. Doostan, B. Vatani, and P. Schwarz, "A novel economic model for price-based demand response," Electric Power Systems Research, vol. 135, pp. 1-9, 2016.

[42] J. Thakur and B. Chakraborty, "Demand side management in developing nations: a mitigating tool for energy imbalance and peak load management," Energy, vol. 114, pp. 895-912, 2016.

[43] F. Arasteh and G. H. Riahy, "MPC-based approach for online demand side and storage system management in market based wind integrated power systems," International Journal of Electrical Power \& Energy Systems, vol. 106, pp. 124-137, 2019.

[44] Z. Wang, B. Zhang, J. Yin, and Y. Zhang, "Determinants and policy implications for household electricity-saving behaviour: evidence from Beijing, China," Energy Policy, vol. 39, no. 6, pp. 3550-3557, 2011.

[45] D. R. Bohi, Analyzing Demand Behavior: A Study of Energy Elasticities, RFF Press, Washington, DC, USA, 2013.

[46] S. Mohajeryami, P. Schwarz, and P. T. Baboli, "Including the behavioral aspects of customers in demand response model: real time pricing versus peak time rebate," in Proceedings of the 2015 North American Power Symposium (NAPS), pp. 1-6, Charlotte, NC, USA, October 2015.

[47] F. C. Schweppe, M. C. Caramanis, R. D. Tabors, and R. E. Bohn, Spot Pricing of Electricity, Springer Science and Business Media, Berlin, Germany, 2013.

[48] H. Jalili, M. K. Sheikh-El-Eslami, M. P. Moghaddam, and P. Siano, "Modeling of demand response programs based on market elasticity concept," Journal of Ambient Intelligence and Humanized Computing, vol. 10, no. 6, pp. 2265-2276, 2019.

[49] M. H. Albadi and E. F. El-Saadany, "Demand response in electricity markets: an overview," in Proceedings of the 2007 IEEE Power Engineering Society General Meeting, pp. 1-5, Tampa, FL, USA, June 2007.

[50] D. S. Kirschen, G. Strbac, P. Cumperayot, and D. de Paiva Mendes, "Factoring the elasticity of demand in electricity prices," IEEE Transactions on Power Systems, vol. 15, no. 2, pp. 612-617, 2000.

[51] S. Zhao and Z. Ming, "Modeling demand response under time-of-use pricing," in Proceedings of the 2014 International
Conference on Power System Technology, pp. 1948-1955, Chengdu, China, October 2014.

[52] M. H. Imani, K. Yousefpour, M. T. Andani, and M. J. Ghadi, "Effect of changes in incentives and penalties on interruptible/ curtailable demand response program in microgrid operation," in Proceedings of the 2019 IEEE Texas Power And Energy Conference (TPEC), pp. 1-6, College Station, TX, USA, Feburary 2019.

[53] M. P. Moghaddam, A. Abdollahi, and M. Rashidinejad, "Flexible demand response programs modeling in competitive electricity markets," Applied Energy, vol. 88, no. 9, pp. 3257-3269, 2011.

[54] C. Yanxin, Y. Xiang, L. Junyong, G. Chenghong, W. Zhang, and X. Weiting, "Incentive-based demand response model for maximizing benefits of electricity retailers," Journal of Modern Power Systems and Clean Energy, vol. 7, no. 6, pp. 1644-1650, 2019.

[55] F. E. Pacheco and J. C. Foreman, "Microgrid reference methodology for understanding utility and customer interactions in microgrid projects," The Electricity Journal, vol. 30, no. 3, pp. 44-50, 2017. 